\title{
A study of Pressure-Sinkage Relationship Used in a Tyre-Terrain Interaction
}

\author{
N. D. SALMAN ${ }^{1,2}$, P. KISS 3 \\ 1Szent István University, Mechanical Engineering Doctoral School, Institute of Process Engineering, \\ Salman.Nihal.Dawood@phd.uni-szie.hu \\ ${ }^{2}$ Middle Technical University (MTU), Baquba Technical Institute, Baghdad, Iraq, nihald2005@yahoo.com \\ ${ }^{3}$ Szent István University, Faculty of Mechanical Engineering, Institute of Process Engineering, \\ kiss.peter@gek.szie.hu
}

Abstract. The vehicle applies a normal load to the terrain, which causes sinkage and motion resistance. To forecast the normal pressure distribution on the interface of a vehicle-terrain and the tractive performance of a vehicle, the response of the terrain to normal load (which is characterized by pressure -sinkage relationship equations) must be measured. This paper presents the common conventional pressure sinkage models used in terramechanic and the modification that happened to this models. In addition the features of the new models.

\section{Introduction}

The wheel was invented since $3500 \mathrm{BC}$, and the understanding of this simple invention was man's request, so his enchantment for its improvement still appears to be unabated even in this technologically advanced era of space exploration, robotics, and microelectronics. The increasing demand for better mobility over a broader range of terrain by resource industries, coupled with the greater awareness of environmental preservation and energy conservation, has stimulated persistent interest in the study of vehicle-terrain interaction [1].

Modelling the interaction of a vehicle with the terrain is the critical part of the vehicle performance evaluation, tyre/terrain interaction is a very sophisticated research topic in terramechanics, transportation and pavement engineering. It generally covers issues on terrain compaction, rutting, tyre traction, dynamic terrain response, mobility and rolling resistance. Obtaining accurate solutions to tyre/terrain interaction can directly help us understand how tyre type and terrain condition affect the overall tyre performance and terrain response. These predictions of tyre/ terrain interaction constitute the foundation for engineers to evaluate ground condition and vehicle trafficability. Therefore, study on tyre/terrain interaction helps in many levels of decision making on off-road and pavement structure design, vehicle design and control ground overly deformation. It has been qualitatively understood that ground response is directly related to the tyre structure, inflation pressure, soil properties, tyre/ terrain interface properties, and vehicle load [2].

The mechanical properties of terrains are usually divided into bearing (which is characterized by pressure-sinkage relationship equations) in the normal direction and shearing in the tangential 
direction. Soil physical properties affect the tractive performance of a vehicle by changing the soil strength characteristics under different conditions. The classification and the measurement of the soil physical properties depend on the requirements of the individual user [3].

The pressure-sinkage plays an essential role in terramechanics. They are used to derive sinkage and resistance, which are in turn used to derive performance metrics such as thrust, and drawbar pull [4]. Most of the pressure-sinkage models assume that the contact area between a wheel and soil can be approximated as a flat plate. Over the years, a variety of methods, ranging from empirical to theoretical, for predicting the performance of tracked and wheeled vehicles over unprepared terrain have been developed or proposed [5],[6].

The pressure-sinkage model can typically represent the soil strength or stiffness, hence is a key measure in soil mechanics that determines whether or not the soil will be stable or how much it will deform [7].

\section{Pressure sinkage relationship}

\subsection{Bevameter technique}

Bekker M.G. developed the Bevameter technique (schematically shown in Figure 1) that makes it possible to define both the compressive and the shear strength parameters. The Bevameter technique consists of two separate tests, a plate penetration test and a shear test. In the penetration test, the normal pressure-sinkage relationship is measured with two sizes of plates, with radii $b 1<b 2$, which are forced into the soil. The shear stress-displacement relationship is measured with shear rings or plates. Three soil shear parameters, i.e. cohesion , the angle of internal friction $\emptyset$, and tangent modulus

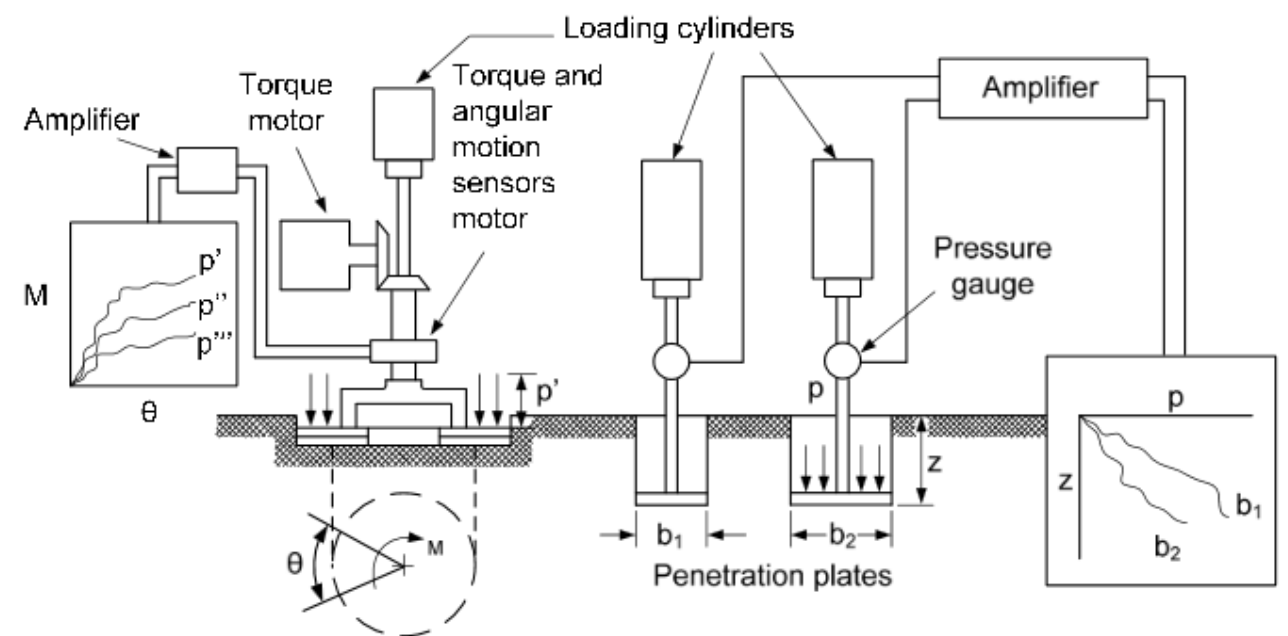

$\mathrm{K}$, are calculated from the shear tests, based on the analogy of grousers on tracked vehicles [6].

Figure 1. Schematic diagram of Bevameter [6]. 


\subsection{Conventional models}

Since the 1913s, several pressure-sinkage relationships have been proposed. Bernstein, Agricultural Engineering was the main concern for his work, experimentally proved that if a plate penetrates the soil to a depth $\mathrm{z}$ under a given pressure $\mathrm{p}$, then the experimental pressure-sinkage curve obtained could be covered with the following equation:

$$
p \cong k z^{0.5}
$$

where $\mathrm{p}$ is the normal pressure, $\mathrm{k}$ is a modulus of inelastic deformation, $\mathrm{z}$ is the sinkage, and 0.5 is the exponent of sinkage [8].

This equation was later revised and generalized by Goriatchkin to take the following form:

$$
p=k z^{n}
$$

where $\mathrm{n}$ is the sinkage exponent, and it can take any value between zero and approximately one as in Figure 2. This model was developed by noting that the pressure-sinkage relationship for a flat plate fits the form of a power function. As such, $\mathrm{k}$ and $\mathrm{n}$ are curve fitting constants that fit experimentally observed data for a soil.

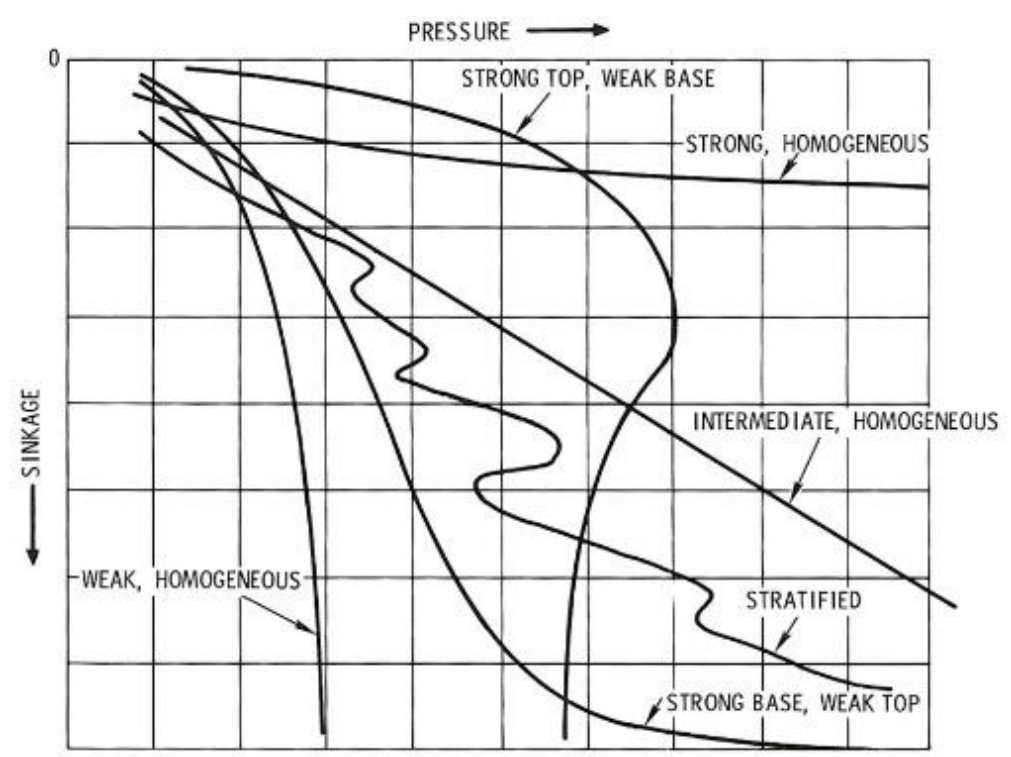

Figure 2. Typical pressure-sinkage curves [9].

Bekker modified the Bernstein-Goriatchkin models to develop a pressure-sinkage relationship for homogeneous soil by replacing $\mathrm{k}$ in equation (2) with the $k_{c}$ and $k_{\emptyset}$ parameters, the Bekker model covered by following equation [9]:

$$
p=\left(\frac{k_{c}}{b}+k_{\varnothing}\right) z^{n}
$$

where $b$ the plate width used in the penetration test, $\mathrm{k}_{\mathrm{c}}$ the pressure-sinkage parameter due to the cohesive effects, $k_{\varnothing}$ the pressure-sinkage parameter due to the frictional effects, and $n \in I R^{+}$is an exponent of deformation. The parameters are usually measured by plate-sinkage experiments with 
rectangular or circular plates [10].The values of $\mathrm{p}$ and $\mathrm{z}$ are measured while the parameters $\mathrm{k}_{c}, k_{\emptyset}$ and $\mathrm{n}$ are derived by fitting experimental data to the above equation (3) [6].

Reece mentioned that the pressure-sinkage relationship expressed in equation (3) is unsatisfactory, since the dimension of soil parameters $k_{c}$ and $k_{\emptyset}$ are dependent on $\mathrm{n}$. This brings about further problems in relations developed based on the equation (3). Therefore, the pressure-sinkage relation, equation (3), replaced to take the following form:

$$
p=\left(c \grave{k}_{c}+\gamma b \grave{k}_{\varnothing}\right)\left(\frac{z}{b}\right)^{n}
$$

where $\grave{k}_{c}, \grave{k}_{\emptyset}$, and $\mathrm{n}$ are new dimensionless pressure-sinkage parameters, and $\gamma$ is the specific weight of the terrain [5]. $\dot{k}_{c}$ can be neglected for cohesionless sand and $\dot{k}_{\emptyset}$ can be neglected for frictionless clay. J.Y.Wong found that both the Bekker and the Reece pressure-sinkage models can be used for mineral soils and suggested the weighted least squares method to be used to determine these soil parameters [6]. Saakyan offered simplest flat plate pressure- sinkage relationship equation (5) derived from the Boussinesq theory of the elastic half space [11]:

$$
p=k\left(\frac{z}{D}\right)^{n}
$$

where $\mathrm{D}$ is the diameter of the indenter. The exponent $\mathrm{n}$ characterises the deformation and compaction behaviour of soil under vertical loading. It is mainly influenced by the moisture content and particle size distribution of soil. Equation (5) not applicable to wet soil.

Kacigin and Guskov proposed the following analytical relationship (6) between the pressure of plate ground and sinkage for soils with hardpan [12].

$$
z=\frac{B_{i}}{k_{z}} \operatorname{arctanh}\left(\frac{p}{B_{i}}\right)
$$

Where: $k_{\mathrm{z}}$ is Kacigin and Guskov's parameter of a load-sinkage curve. $B_{\mathrm{i}}$ is a soil ultimate compressive strength, corresponds to bearing capacity of soil with infinite hardpan. $k_{\mathrm{z}}$ and $B_{\mathrm{i}}$ parameters are independent of the plate shape and dimensions and depend only on soil type and moisture content.

\subsection{Modification of pressure-sinkage model in the literature}

\subsubsection{Load-Sinkage Analytical (LSA) model}

Lyasko M. (2010) presented LSA model, this model is based on a test observed relationship of stress distribution in the soil under a plate contact area as:

$$
\begin{aligned}
& \sigma_{z}=\frac{J p_{\max }}{1+\left(\frac{z}{A_{0} B}\right)^{2}} \\
& A_{0}=0.64\left(1+\frac{B}{H}\right), J=\frac{0.03+\frac{L}{B}}{0.6+0.43 \frac{L}{B}}
\end{aligned}
$$


Where $A_{0}$ is the dimensionless coefficient of plate width and hardpan depth effect on sinkage, $B$ is the plate width of none circular contact area, $L$ is the plate length of a contact area $(\mathrm{m}), \mathrm{H}$ is the hardpan depth or thickness of soil upper relatively soft layer which can be deformed under a load (m).

As shown in equation (7), there is a direct correlation between stresses $\left(\sigma_{z}\right)$ under a plate contact area and maximum pressure $\left(\mathrm{p}_{\max }\right)$, not average ground pressure $\mathrm{p}$. Numerous tests conducted with plates tracked and wheeled vehicles and their scale models in soil bins and fields in different soil conditions the Author found this relationship. The Author reveals the application of equation (7) in Figure (3) where Stresses under a circular plate of $0.3 \mathrm{~m}$ diameter were measured at depth $0.2,0.35$ and $0.5 \mathrm{~m}$ in

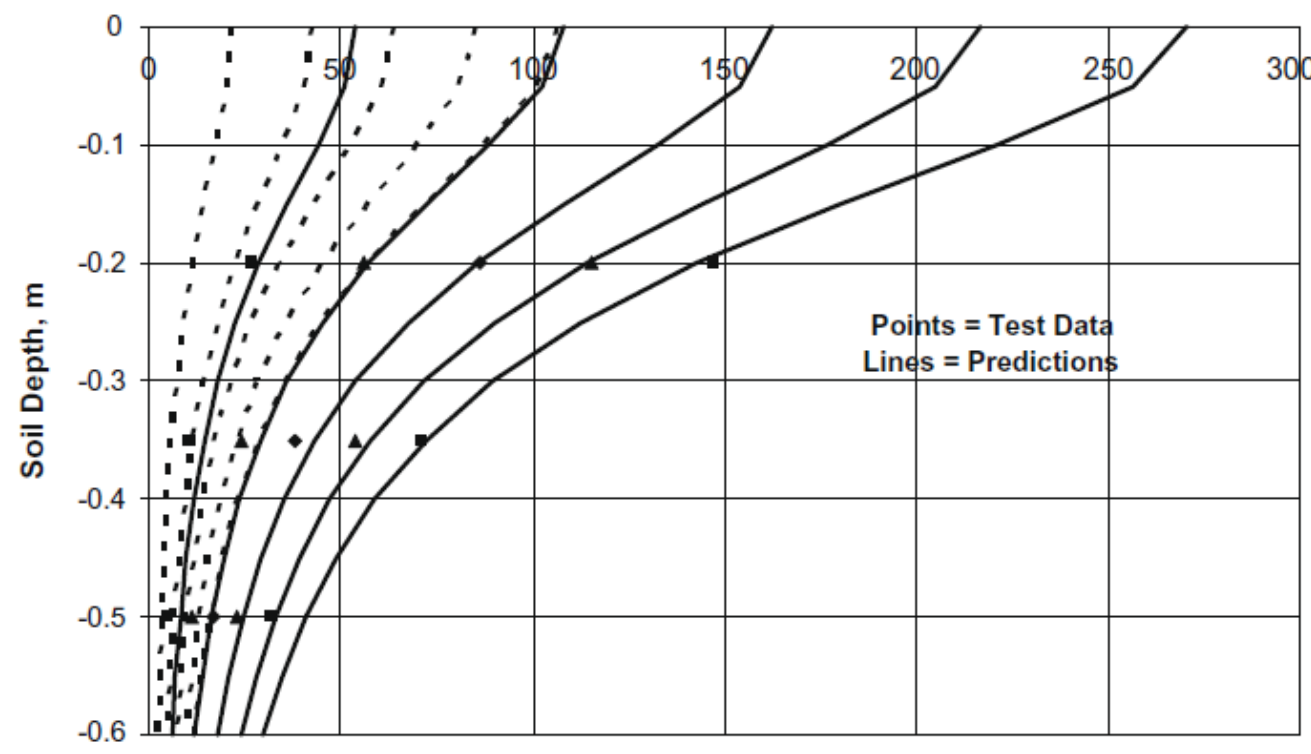

Normal Stress Under 0.3 m Diameter Plate, kPa

the sand with $\mathrm{H}=1 \mathrm{~m}$. Normal pressure was varied: $\mathrm{p}=21.2,42.5,63.7,85.0$ and $106.2 \mathrm{kPa}$.

Figure 3. Normal stress - soil depth curves in the sand for a circular plate of $0.3 \mathrm{~m}$ diameter [13].

The pressure distribution in contact of a rigid plate and soil is not a uniform, so the Author proposed a maximum pressure form:

$$
p_{\max }=\xi p
$$

Coefficient $\xi$ depends on plate width B and for typical soils, and tractor operating conditions can be obtained from the following empirical equation:

$$
\begin{aligned}
\xi & =1+1.86\left(\frac{x}{2}+\frac{x^{2}}{3}-\frac{x^{3}}{5}\right) \\
x & =2.5(1-\exp (-3.74 B))
\end{aligned}
$$

The Author showed the relationship between the contact pressure concentration coefficient $\xi$ and plate width B in Figure 4. 


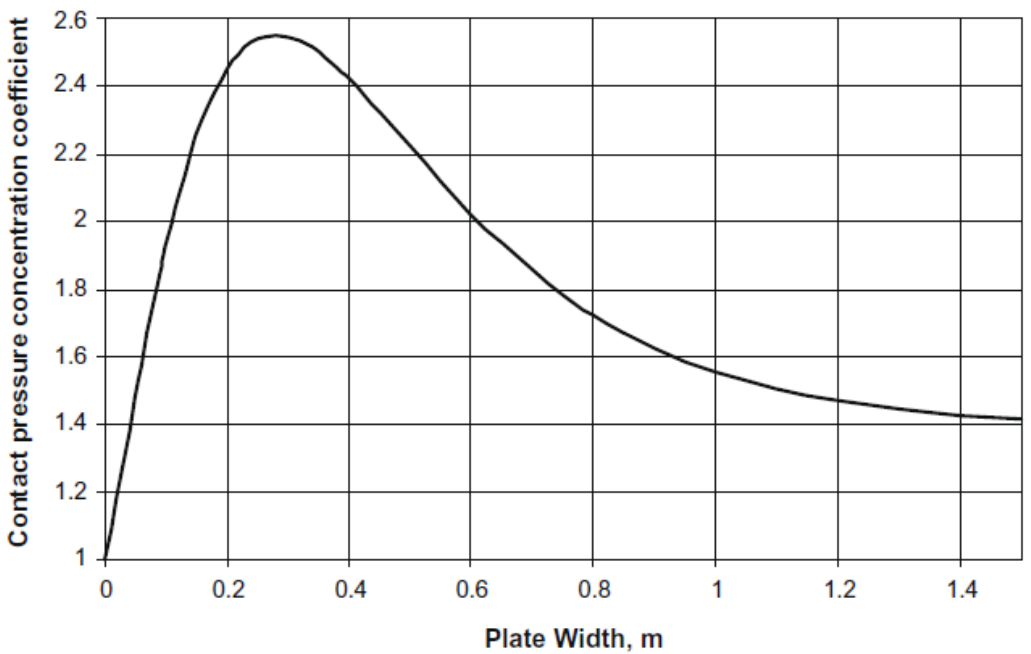

Figure 4. Contact pressure concentration coefficient n vs plate width B [13].

The Author developed equation (8) as a new relationship of pressure p and sinkage z:

$$
p=\frac{1}{\frac{D_{1}}{B_{i}}+\frac{D_{2}}{E z} w \beta \xi}
$$

Where : $D_{1}=\frac{2}{\pi} \arctan \left(\frac{\pi(H-z)}{2 B}\right), D_{2}=\arctan \left(\frac{H-z}{A_{0} B}\right)$ and $\omega=A_{0} J(1.14 \leq \omega \leq 2.15), \omega$ is a coefficient depending on soil hardpan, shape and dimensions of plate contact area.

So, a new LSA model includes load, sinkage, plate dimensions and invariant soil parameters. The Author validated LSA model by many fields and soil bin tests, and it is in agreement with test results. The LSA model used as a basis for predictions of motion resistance and sinkage of tracked and wheeled vehicles in different soils.

\subsubsection{Modified model for small, rigid wheels}

Meirion G. G and Spenko M. (2011) proposed a modified pressure-sinkage model for small, rigid wheels on deformable terrains. A new model is proposed to account for the dependence on wheel diameter, the equation of the new model is:

$$
p=\hat{k} z^{\hat{n}} D^{\hat{m}}
$$

Where $\hat{k}$ is the proposed sinkage modulus $\left(\mathrm{kN} / m^{\hat{n}+\hat{m}+2}\right), \hat{n}$ is the proposed sinkage exponent, $\mathrm{D}$ is the wheel diameter, and $\widehat{m}$ is the diameter exponent.

The improvement in the suggested model stems from the inclusion of $D^{\widehat{m}}$, which ensures that the curvature of the pressure-sinkage relationship is a function of both sinkage and diameter. There are three different types of soil used for validating the modified model and the constants $\hat{k}$; and $\widehat{m}$ for each of the soils tested are shown in Table 1 . 
International Journal of Engineering and Management Sciences (IJEMS) Vol. 4. (2019). No. 1

DOI: 10.21791/IJEMS.2019.1.24.

Table 1. Soil properties of the suggested model [14].

\begin{tabular}{|c|c|c|c|}
\hline Soil properties & Dry sand & Calcium silicate & Moist earth \\
\hline$\hat{k}\left(\mathrm{kN} / m^{\hat{n}+\hat{m}+2}\right)$ & 1604 & 16.7 & 78.7 \\
\hline$\hat{n}$ & 0.8 & 0.48 & 0.88 \\
\hline$\widehat{m}$ & 0.39 & 0.00 & -0.49 \\
\hline
\end{tabular}

The Authors explain the improvement in the pressure- sinkage model in Figure 5.

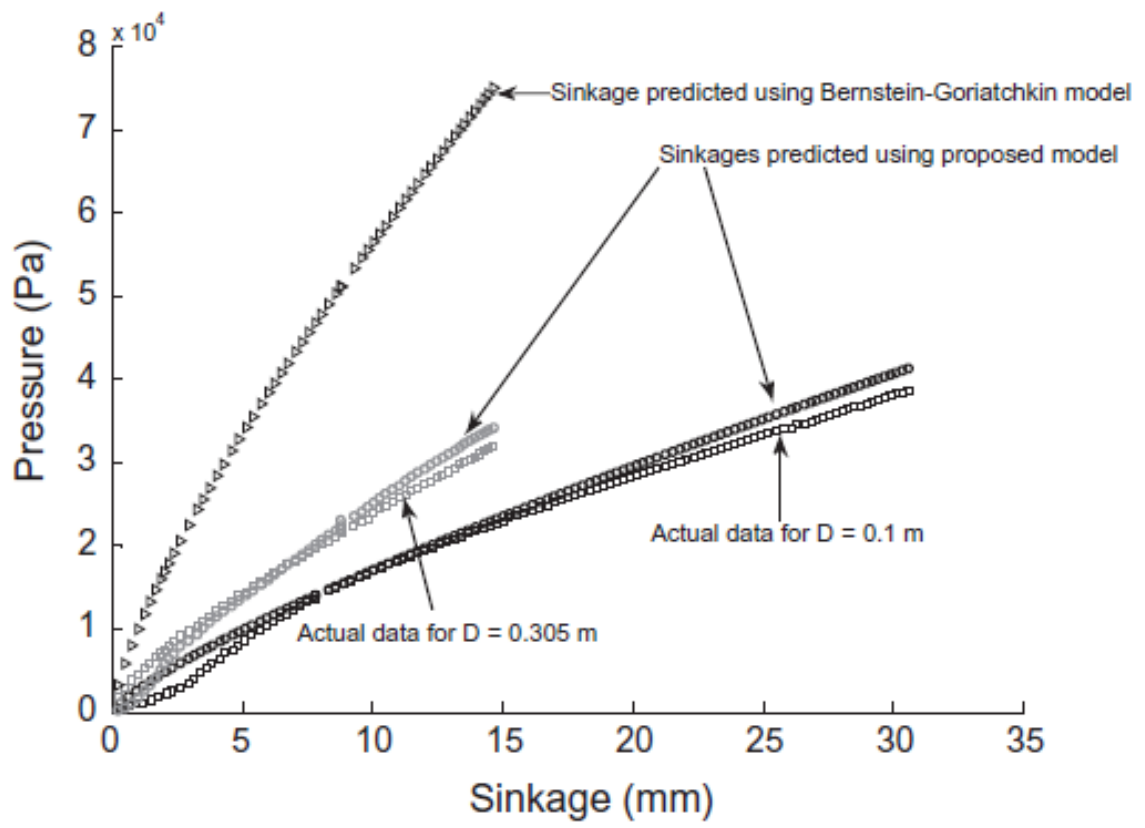

Figure 5. Comparison of Bernstein-Goriatchkin and proposed model on dry sand [14].

The Authors validate the proposed sinkage model, experiments using the vehicle-terrain testbed. The tests utilized rigid wheels of diameters $0.114 \mathrm{~m}, 0.170 \mathrm{~m}$ and $0.229 \mathrm{~m}$ under the conditions given in Table 2.

Table 2. Experimental test conditions [14].

\begin{tabular}{|c|c|c|c|}
\hline Wheel diameter D (m) & Wheel width b (m) & $\begin{array}{c}\text { Forward } \\
\text { velocity }(\mathrm{cm} / \mathrm{s})\end{array}$ & Normal load W (N) \\
\hline 0.17 & 0.085 & 10 & 46 and 84 \\
\hline
\end{tabular}

The Author presented comparison for the proposed model with Bekker model as shown in Figure 6 . this comparison revealed where the Bekker's equation clearly over-estimates the pressure required to achieve the experimentally found level of sinkage. While proposed model adheres to the pressuresinkage data with reasonable accuracy.

The suggested model was found to yield an average improvement in sinkage prediction accuracy of $41.8 \%$. The new model can be applied to a wide variety of applications.

In 2013 the same Authors proposed further improvements to the pressure-sinkage model for small diameter wheels that account for both wheel width and diameter on compacted soils. The new model is:

$$
p=\hat{k} r^{\hat{n}}\left(\cos \theta-\cos \theta_{s}\right)^{\hat{n}}(b l)^{\hat{m}}
$$


Where is the $r$ : wheel radius (m), $\hat{n}$ : proposed sinkage exponent, $\theta$ is the angle along wheel-soil contact $\operatorname{arc}(\mathrm{deg}) ; \theta_{\mathrm{s}}$ is the static wheel-soil contact angle (deg), b is the wheel width (m), $\mathrm{l}$ is the horizontally projected length of the wheel-soil contact patch and given by $l=\sqrt{D z_{0}-z_{0}^{2}}$.

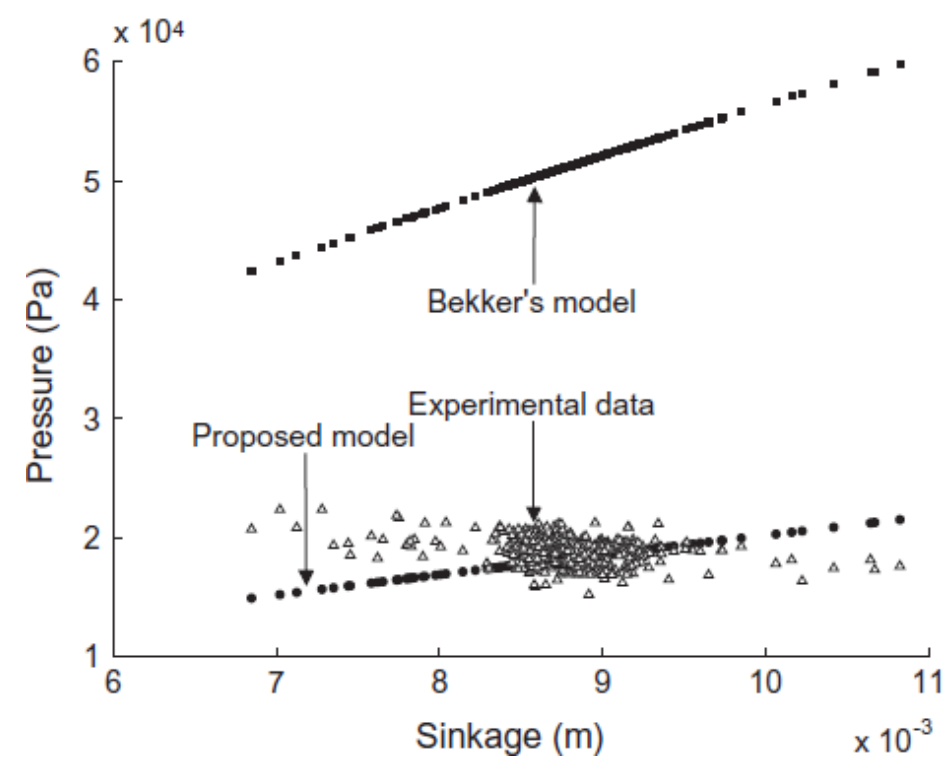

Figure 6. Comparison of experimental sinkage data fit with Bekker and proposed models [14].

The results took for 125 pressure-sinkage tests using 35-wheel geometries on clay/silt mix, in addition, the X-ray images of sub-surface soil deformation used to validate the model visually. The Authors compared the new model with Bekker and Reece model and the comparison shown in Figure 7.

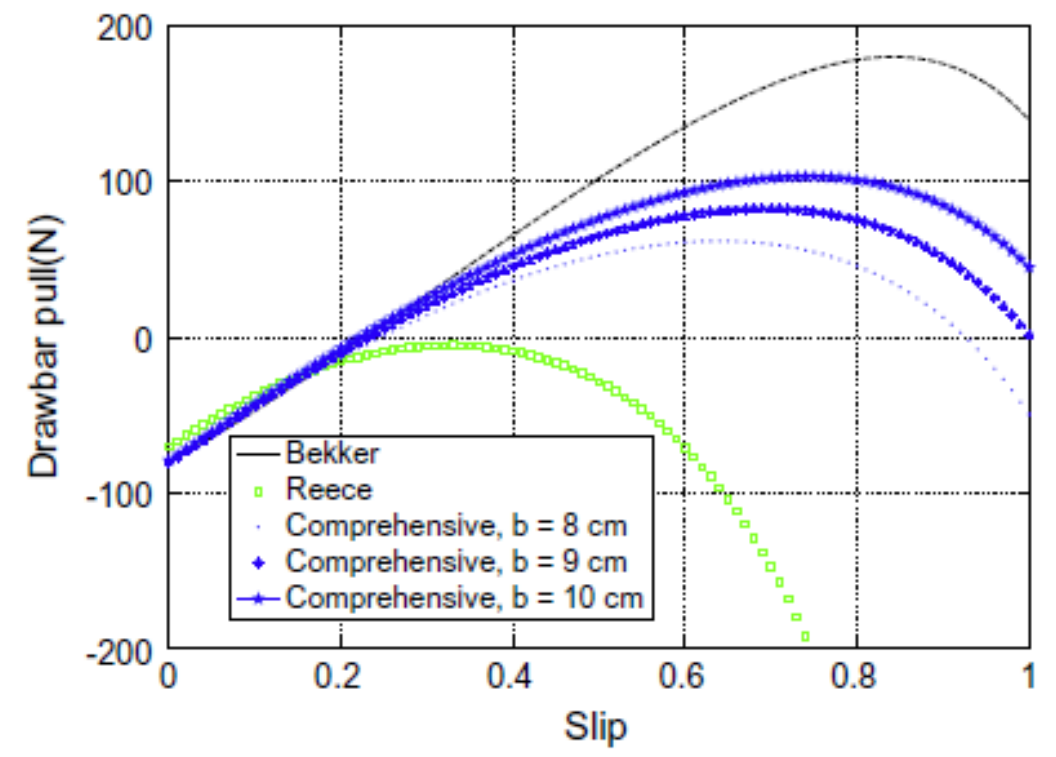

Figure 7. Comparison of traction predictions using Bekker, Reece, and the diameter and width dependent model proposed [15].

The new model showed that the effect of wheel width on the pressure-sinkage relationship is like that of a change in wheel diameter. Experimental results indicate that the suggested model offers better 
predictive capabilities than its predecessors in both laboratory and field tests. So, the new model is fitted for many applications and many kinds of terrain.

\subsubsection{New perspective and related equations on characterizing pressure-sinkage relationship}

Ding L. et. Al. (2014) proposed new perspective and related equations on characterizing pressuresinkage relationship equations based on the analysis of conventional models and experimental results. A new concept of characterizing the pressure-sinkage relationship that can reflect dynamics phenomena, the coupling effect, the effect of dimensions of the mobile mechanism, etc. A pressuresinkage relationship equation for characterizing the terrain is as follows:

$$
p=k_{S} z \lambda_{N}
$$

where $\mathrm{k}_{\mathrm{s}}$ is the stiffness modulus of the terrain in units of $\mathrm{Pa} / \mathrm{m}, \lambda_{N}$ is a dimensionless function used to reflect the nonlinear part of the sinkage exponent. $\lambda_{N}$ can modulate the curve of the pressure-sinkage relationship around the line $\mathrm{k}_{\mathrm{s}} \mathrm{z}$ to improve the accuracy. The Authors classified the terrain into five groups according to their bearing properties, as shown in Table 3 and 4.

The maximum pressures for the soils of groups I, II, and III were set at $40 \mathrm{kPa}, 300 \mathrm{kPa}$, and $1500 \mathrm{kPa}$, respectively, and the maximum deformation of the terrains of groups IV and V were set at $0.1 \mathrm{~m}$. It was found that the terrains with sinkage exponents larger than 0.3 characterized by Equation 14

$$
\begin{aligned}
& p=k_{S} z^{\left(n_{0}+n_{1} z\right)} \\
& \lambda_{N}=\left(\frac{z}{z_{0}}\right)^{n_{0}-1+n_{1}\left(\frac{z}{z_{0}}\right)}, z_{0}=1 \mathrm{~m}
\end{aligned}
$$

In the case of the plastic terrains of group V, the data fitting error with Equation (14) was large with approximately $85 \%$ goodness of fit. Thus, Equation (15) is proposed to improve the model accuracy:

$$
\begin{aligned}
& p=k_{S} z\left(\frac{1}{n_{0}+n_{1} z+n_{2} z^{2}}\right) \\
& \lambda_{N}=\frac{1}{n_{0}+n_{1} \frac{z}{z_{0}}+n_{2}\left(\frac{z}{z_{0}}\right)^{2}}, \mathrm{z} 0=1 \mathrm{~m} .
\end{aligned}
$$

The values of $\mathrm{k}_{\mathrm{s}}, \mathrm{n}_{0}, \mathrm{n}_{1}, \mathrm{n}_{2}$, and goodness of fit are shown in Table 4 . 
International Journal of Engineering and Management Sciences (IJEMS) Vol. 4. (2019). No. 1

DOI: 10.21791/IJEMS.2019.1.24.

Table 3. Parameters identified using equation (14) and goodness of fit [3].

\begin{tabular}{|c|c|c|c|c|c|c|c|c|c|c|}
\hline Group & No. & Terrain & $\begin{array}{l}\text { Moisture } \\
\text { content }(\%)\end{array}$ & $\begin{array}{l}k_{c} \\
\left(\mathrm{~Pa} / \mathrm{m}^{n-1}\right)\end{array}$ & $\begin{array}{l}k_{\varphi} \\
\left(\mathrm{Pa} / \mathrm{m}^{n}\right)\end{array}$ & $n$ & $\begin{array}{l}K_{\mathrm{s}} \\
(\mathrm{Pa} / \mathrm{m})\end{array}$ & $n_{0}$ & $n_{1}$ & $\begin{array}{l}\text { Goodness } \\
\text { of fit }(\%)\end{array}$ \\
\hline \multirow[t]{3}{*}{$\mathrm{I}(40 \mathrm{kPa})$} & 21 & Snow (Sweden) & - & 10.55 & 66.08 & 1.44 & 95.98 & 1.321 & -1.221 & 100 \\
\hline & 19 & Snow (US) & - & 4.37 & 196.72 & 1.6 & 102.36 & 1.413 & -1.734 & 100 \\
\hline & 20 & (Harrison) & - & 2.49 & 245.90 & 1.6 & 110.13 & 1.395 & -1.786 & 100 \\
\hline \multirow[t]{6}{*}{ II $(300 \mathrm{kPa})$} & 1 & Dry sand (LLL) ${ }^{a}$ & 0 & 0.99 & 1528.43 & 1.1 & 1283.26 & 1.056 & -0.345 & 100 \\
\hline & 16 & Rubicon sandy loam (Wong) & 43 & 6.9 & 752 & 0.66 & 1552.99 & 0.810 & 1.238 & 99.9 \\
\hline & 4 & Sandy loam & 11 & 52.53 & 1127.97 & 0.9 & 2066.87 & 0.952 & 0.444 & 100 \\
\hline & 15 & Upland sandy loam (Wong) & 51 & 74.6 & 2080 & 1.10 & 2734.98 & 1.093 & -0.059 & 100 \\
\hline & 9 & (Thailand) & 55 & 16.03 & 1262.53 & 0.7 & 3078.11 & 0.870 & 1.685 & 99.9 \\
\hline & 2 & Sandy loam & 15 & 5.27 & 1515.04 & 0.7 & 3535.13 & 0.875 & 1.850 & 100 \\
\hline \multirow[t]{3}{*}{ III (1500 kPa) } & 17 & North Gower clayey loam (Wong) & 46 & 41.6 & 2471 & 0.73 & 4040.02 & 0.801 & 0.710 & 100 \\
\hline & 18 & Grenville loam (Wong) & 24 & 0.06 & 5880 & 1.01 & 5782.53 & 1.006 & -0.032 & 100 \\
\hline & 14 & LETE sand (Wong) & - & 102 & 5301 & 0.79 & 9954.61 & 0.896 & 0.900 & 100 \\
\hline \multirow[t]{4}{*}{ IV $(0.1 \mathrm{~m})$} & 7 & (Hanamoto) & 32 & 0.77 & 51.91 & 0.5 & 225.64 & 0.783 & 3.061 & 99.3 \\
\hline & 6 & Sandy loam & 26 & 2.79 & 141.11 & 0.3 & 1101.02 & 0.688 & 4.481 & 95.2 \\
\hline & 8 & Clayed soil & 38 & 13.19 & 692.15 & 0.5 & 3119.29 & 0.783 & 3.061 & 99.3 \\
\hline & 5 & Michigan (Strong, Buchele) & 23 & 11.42 & 808.96 & 0.4 & 4580.27 & 0.737 & 3.750 & 98.2 \\
\hline
\end{tabular}

Table 4. Parameters identified using equation (15) and goodness of fit [3].

\begin{tabular}{|c|c|c|c|c|c|c|c|c|c|c|}
\hline No. & Terrain & Moisture content $(\%)$ & $k_{c}$ & $k_{\varphi}$ & $n$ & $K_{\mathrm{s}}$ & $n_{0}$ & $n_{1}$ & $n_{2}$ & Goodness of fit (\%) \\
\hline 3 & (LLL) & 22 & 2.56 & 43.12 & 0.2 & 588.92 & 0.032 & 17.640 & -47.484 & 98.2 \\
\hline 13 & $(\mathrm{WES})^{\mathrm{a}}$ & 32 & 1.52 & 119.61 & 0.15 & 1326.07 & 0.018 & 17.315 & -39.478 & 98.0 \\
\hline 11 & (WES) & 40 & 1.84 & 103.27 & 0.11 & 1336.90 & 0.011 & 16.861 & -31.096 & 98.2 \\
\hline 12 & Lean clay & 22 & 16.43 & 1724.69 & 0.2 & 16188.23 & 0.032 & 17.640 & -47.484 & 98.2 \\
\hline 10 & Heavy clay & 25 & 12.70 & 1555.95 & 0.13 & 17495.71 & 0.0140 & 17.109 & -35.508 & 98.1 \\
\hline
\end{tabular}

${ }^{a}$ LLL: Land Locomotion Laboratory (LLL).

${ }^{a}$ WES: Waterways Experiment Station.

The Authors compared the theoretical results predicted by Bekker with those estimated by the new equations (14) and (15), shown in Figure 8. The proposed model can fit the theoretical results predicted by Bekker's exponential functions with high accuracy.

\subsubsection{New model to capture and predict the dynamic oscillations}

R.A. Irani et al. proposed model able to capture and predict the dynamic oscillations observed in experimental data from a single-wheel testbed (rigid wheels with grousers) for the sinkage, drawbar pull and normal load. The oscillations are seen in the sinkage, drawbar pull, and normal load caused by the grousers can be accounted for by enhancing the dynamic pressure-sinkage relationship as follow:

$$
p=\left(c \grave{k}_{c}+\gamma b \grave{k}_{\varnothing}\right)\left(\frac{z}{b}\right)^{n}+\left({\grave{k_{g}}}_{\bar{\sigma}_{p}}+\grave{k}_{a} l_{c} d_{\gamma}\right) \sin \left(\frac{\omega_{w}}{n_{g}} t+\Phi\right)
$$

Where $\grave{k}_{g}$ is the dimensionless grouser amplitude coefficient, $\bar{\sigma}_{p}$ is the passive stress, $k_{a}$ is the dimensionless density amplitude coefficient, $\mathrm{L}_{c}$ is the wheel-soil contact arc length $(\mathrm{m}), d_{\gamma}$ is the change is soil density $\left(\mathrm{N} / \mathrm{m}^{3}\right), \mathrm{n}_{\mathrm{g}}$ is the number of grousers, $\mathrm{t}$ is the time, $\omega_{\mathrm{w}}$ is the angular velocity of the wheel ( $\mathrm{rad} / \mathrm{s}), \Phi$ is the an optional phase shift that can be applied to the model. 
International Journal of Engineering and Management Sciences (IJEMS) Vol. 4. (2019). No. 1

DOI: 10.21791/IJEMS.2019.1.24.
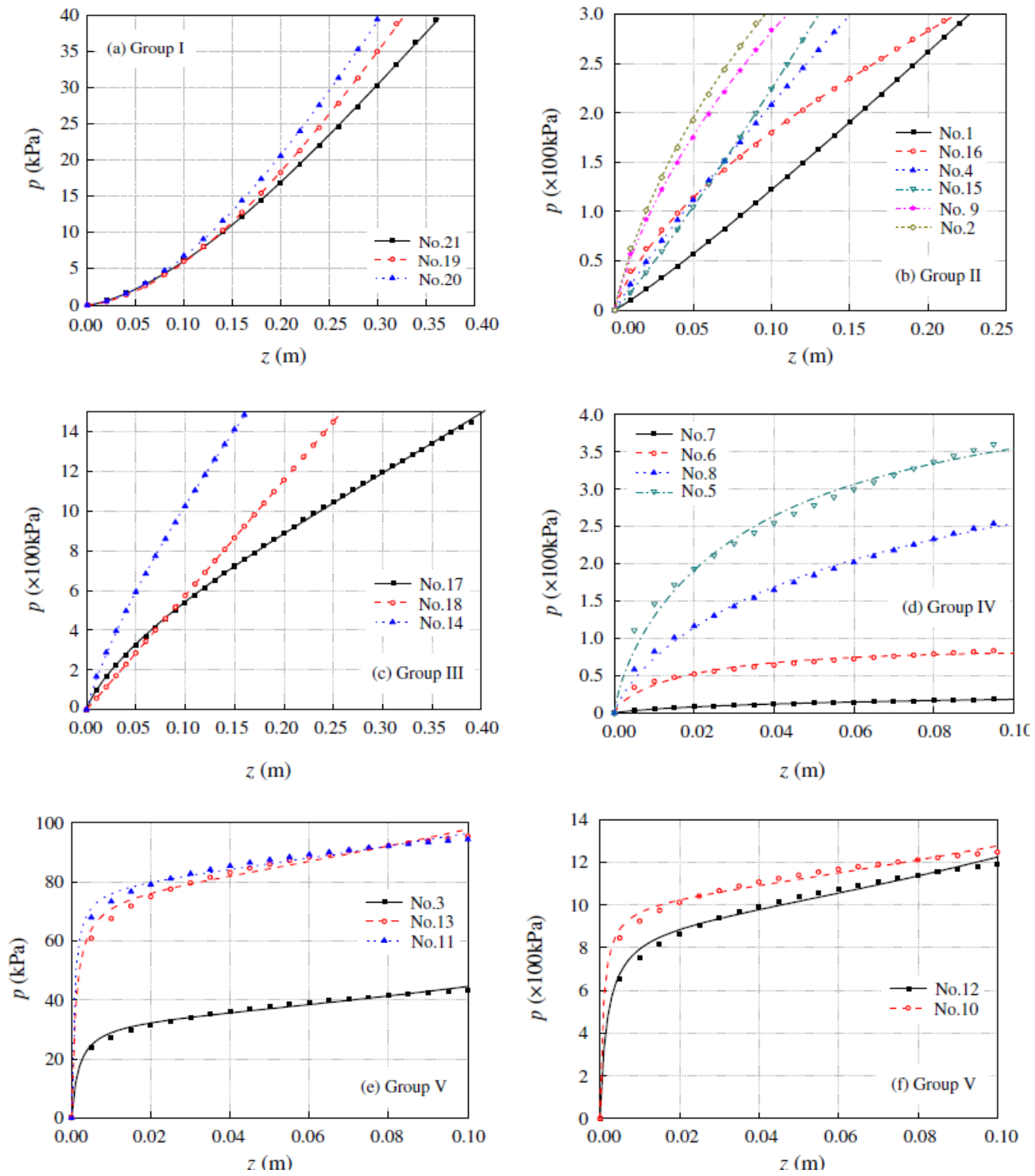

Figure 8. Comparison of the theoretical results predicted by Bekker's equation (the scattered points) and those calculated by the new equations (the successive curves) [3].

The author solved the new model numerically, and the simulation is carried out with MAT-LAB program. The comparison between the experimental and simulation results using the proposed model for sinkage, drawbar pull, and normal load plotted as a function of time are shown in Figure 9. 

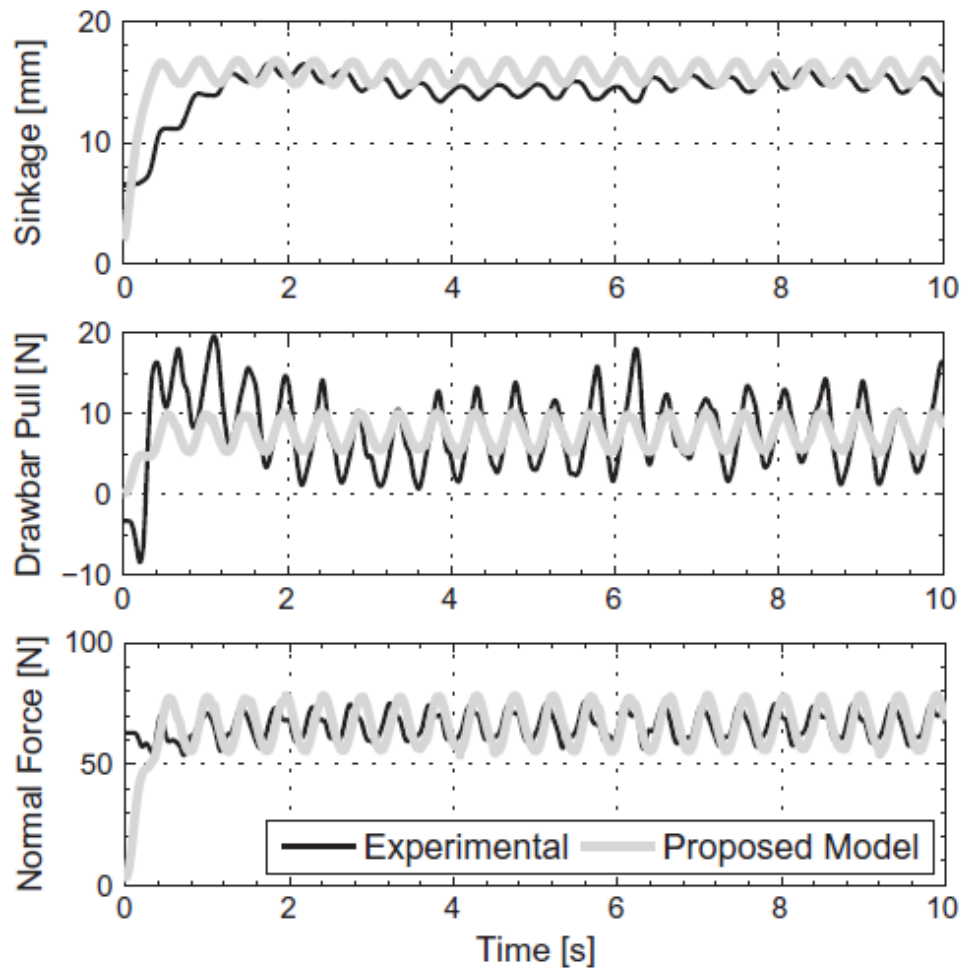

Figure 9. Simulation of a rigid wheel with 16, $10 \mathrm{~mm}$ long grousers, operating at 0.25 slip and a $66 \mathrm{~N}$ normal load overlaid with experimental data [16].

The model improves traditional terramechanic models by showing the dynamic effects of grousers. The additional terms in the model are based on existing soil mechanic theories that vary as a function of soil properties, slip conditions, and vehicle loading.

\section{Summary}

Table 5 shows the features of the new models,

\begin{tabular}{|c|c|c|}
\hline Model name & Features & Basic of the model \\
\hline LSA model & $\begin{array}{l}\qquad p=\frac{1}{\frac{D_{1}}{B_{i}}+\frac{D_{2}}{E z} w \beta \xi} \\
\text { 1. Helps users to evaluate load-sinkage curves } \\
\text { of rigid plates of different shape and } \\
\text { dimensions } \\
\text { 2. Uses invariant soil parameters which do not } \\
\text { depend on plate shape, size or plate-soil } \\
\text { boundary conditions. }\end{array}$ & $\begin{array}{l}\text { The LSA model based on a } \\
\text { test observed the } \\
\text { relationship of stress } \\
\text { distribution in the soil under } \\
\text { a plate contact area. }\end{array}$ \\
\hline $\begin{array}{l}\text { Modified } \\
\text { pressure- } \\
\text { sinkage } \\
\text { model }\end{array}$ & 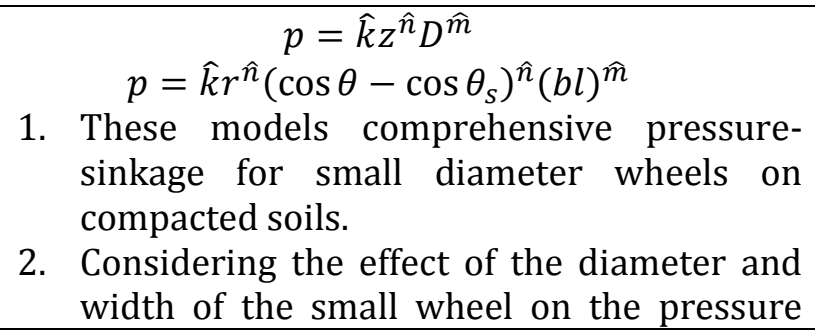 & $\begin{array}{l}\text { Modified Bekker and Reece } \\
\text { model }\end{array}$ \\
\hline
\end{tabular}




\begin{tabular}{|c|c|c|}
\hline & $\begin{array}{l}\text { sinkage. } \\
\text { 3. The experimental results offer better } \\
\text { predictive capabilities than its predecessors } \\
\text { in both laboratory and field tests. }\end{array}$ & \\
\hline $\begin{array}{c}\text { A new } \\
\text { perspective } \\
\text { on } \\
\text { characterizing } \\
\text { pressure- } \\
\text { sinkage } \\
\text { relationship }\end{array}$ & $\begin{array}{l}\qquad p=k_{S} z \lambda_{N} \\
\text { 1. The model with two meaningful parameters } \\
\text { can fit the results of Bekker's model with } \\
\text { three parameters and high goodness of fit } \\
\text { 2. The model applied to small rigid wheels } \\
\text { that move on the deformable terrain. } \\
\text { 3. it can be applied to estimating the } \\
\text { pressure-sinkage relationship during } \\
\text { wheel-terrain interaction with dynamic } \\
\text { sinkage. }\end{array}$ & Based on Bekker model \\
\hline $\begin{array}{l}\text { Model to } \\
\text { capture and } \\
\text { predict the } \\
\text { dynamic } \\
\text { oscillations }\end{array}$ & $\begin{array}{l}p=\left(c \grave{k}_{c}+\gamma b \grave{k}_{\phi}\right)\left(\frac{Z}{b}\right)^{n} \\
\qquad+\left(\grave{k_{g}} \bar{\sigma}_{p}+\grave{k}_{a} l_{c} d_{\gamma}\right) \sin \left(\frac{\omega_{w}}{n_{g}} t+\Phi\right) \\
\text { 1. The new relationship can capture the } \\
\text { dynamic oscillations observed for a wheel } \\
\text { with grousers. } \\
\text { 2. the numerical simulations were carried out } \\
\text { in the MATLAB/Simulink environment }\end{array}$ & Modified Reece model \\
\hline
\end{tabular}

Table (5) Summary of the features of pressure sinkage models.

\section{Conclusion}

The methods for modelling pressure sinkage of the wheeled vehicles on deformable terrains are influenced by different terrain properties in addition to design and operational parameters. These methods are extended from very simple empirical methods to analytical methods. Conventional models of characterizing bearing properties of terrains for vehicles are poor adaptability and extrapolation ability; definitions of parameters are nonintuitive. This article covers some basic models of pressure sinkage and modification that have been on it to make it more adaptable. A description is given for selected studies to familiarize the reader with the general terminologies, formulations and modelling approaches.

\section{Acknowledgment}

This work was supported by the Stipendium Hungaricum Programme and by the Mechanical Engineering Doctoral School, Szent István University, Gödöllő, Hungary.

\section{References}

[1] J. Y. Wong (1991) Some recent developments in vehicle-terrain interaction studies. Journal of Terramechanics, 28(4) pp. 269-288.

[2] K. Xia - Y. Yang (2012) Three-dimensional finite elementmodeling of tire/ground interaction. International Journal for Numerical and Analytical Methods in Geomechanics, 36 pp. 498-516. 
[3] L. Ding - H. Gao - Z. Deng - Y. Li - G. Liu (2014) New perspective on characterizing pressuresinkage relationship of terrains for estimating interaction mechanics. Journal of Terramechanics, 52(1) pp. 57-76.

[4] G. Ishigami (2008) Terramechanics-based analysis and control for lunar/planetary exploration robots. Dissertation, Department of Aerospace Engineering, Tohoku University,

[5] A. R. Reece (1965) Principles of soil-vehicle mechanics. Proceedings of the Institution of Mechanical Engineers, 180(1) pp. 45-66.

[6] J. Y. Wong (2001) Theory of Ground Vehicles. John wily and Sons, Third Edition, Canada.

[7] Y. Gao (2016) Contemporary Planetary Robotics. Wiley-vch verlag gmbh \& Co. Kgaa, Germany.

[8] R. Bernstein (1913) Probleme zur experimentellen Motorpflugmechanik. Motorwagen,16(9) pp. 199-206.

[9] M. G. Bekker (1969) Introduction to terrain-vehicle systems. Michigan Publishing ,First Edition, University of Michigan.

[10] M. G. Bekker (1956) Theory of Land Locomotion: The Mechanics of Vehicle Mobility. Michigan Publishing,University of Michigan.

[11] G. Sitkei - G. Pillinger - L. Máthé - L. Gurmai - P. Kiss (2018) Methods for generalization of experimental results in terramechanics. Journal of Terramechanics.

[12] P. Kiss (2001) Terepen Mozgo Jarmuvek Energetikajanak Egyes Kerdesei. Dissertation, Szent Istvan University, Gödöllő, Hungary.

[13] M. Lyasko (2010) LSA model for sinkage predictions. Journal of Terramechanics, 47(1) pp. 1-19.

[14] G. Meirion Griffith- M. Spenko(2011) A modified pressure-sinkage model for small, rigid wheels on deformable terrains. Journal of Terramechanics, 48(2) pp. 149-155.

[15] G. Meirion Griffith - M. Spenko (2013) A pressure-sinkage model for small-diameter wheels on compactive, deformable terrain. Journal of Terramechanics, 50(1) pp. 37-44.

[16] R. A. Irani- R. J. Bauer - A. Warkentin (2011) A dynamic terramechanic model for small lightweight vehicles with rigid wheels and grousers operating in sandy soil. Journal of Terramechanics, 48(4) pp. 307-318. 